\title{
Riscos, vulnerabilidades e proteção no enfrentamento da Covid-19 no Amazonas: notas reflexivas
}

\section{Risks, vulnerabilities and protection in coping at Covid-19 in Amazonas: reflective notes}

\author{
Emily Rosário Menezes ${ }^{1}$, Laimara Oliveira da Fonseca ${ }^{2}$, Breno de Oliveira Ferreira ${ }^{3}$ \\ 1 Universidade Federal do Amazonas, Manaus, Amazonas, Brasil. https://orcid.org/0000-0002-0103-9770 E-mail: \\ menezesrosarioemily@gmail.com \\ 2 Universidade Federal do Amazonas, Manaus, Amazonas, Brasil. https://orcid.org/0000-0001-5796-7376 E-mail: \\ laimaraoliveira@gmail.com \\ ${ }^{3}$ Universidade Federal do Amazonas, Manaus, Amazonas, Brasil. https://orcid.ora/0000-0002-0979-3911 E-mail: breno.oli@hotmail.com \\ *autor para correspondência.
}

\author{
Palavras-chave \\ Amazonas \\ Covid-19 \\ Saúde Pública \\ Vulnerabilidade
}

\begin{abstract}
O presente estudo trata-se de um ensaio crítico acerca da pandemia de Covid-19 no estado do Amazonas, que se destaca nacionalmente pelo colapso sanitário enfrentado. Diante disso, objetiva-se apresentar fatores de riscos regionais e de vulnerabilidades que contribuíram para a eclosão desta crise e, para isto, o estudo apoiouse em artigos, mídias jornalísticas e outras fontes secundárias. Na discussão, foram priorizadas as dimensões social e programática como aporte teórico. Na dimensão social, foram analisados cenários socioculturais que impactam nas práticas relacionadas à exposição ou à proteção $e$, na dimensão programática, foram consideradas as políticas e serviços de diversos setores intervenientes no processo de vulnerabilidade. Assim, percebe-se que esta crise é atravessada pela ótica interseccional, plasma-se pela escassez de políticas públicas de saúde voltadas para a realidade amazônica e desemboca na dificuldade de adesão às medidas de isolamento. Por fim, há uma urgência em ações intersetoriais que reconheçam as vulnerabilidades específicas do contexto amazônico como fatores determinantes para a garantia de proteção e saúde.
\end{abstract}

\begin{abstract}
The present study is a critical essay about the Covid-19 pandemic in the state of Amazonas, which stands out nationally for the health collapse faced. In view of this, we aim to present regional risk and vulnerability factors that contributed to the outbreak of this crisis and, for this, we rely on articles, news media and other secondary sources. In the discussion, the social and programmatic dimensions were prioritized as a theoretical contribution. In the social dimension, we analyze socio-cultural scenarios that impact practices related to exposure or protection and, in the programmatic dimension, we consider the policies and services of different sectors involved in the vulnerability process. Thus, we see that this crisis is crossed by the intersectional perspective, is shaped by the scarcity of public health policies focused on the Amazonian reality and leads to the difficulty of adhering to isolation measures. Finally, there is an urgent need for intersectoral actions that recognize the specific vulnerabilities of the Amazon context as determining factors for ensuring protection and health.
\end{abstract}

Amazonas

Public Health

Vulnerability

\section{INTRODUÇÃO}

A Covid-19 é causada pelo coronavírus SARS-CoV-2 e se manifesta desde infecções assintomáticas a quadros respiratórios graves, podendo ser fatal em alguns casos, por isso tem gerado tensões, crises e embates de amplitude global entre diferentes áreas. Foi em março de 2020, quando o vírus tinha chegado a mais de cem países, que a Organização Mundial da Saúde (OMS) declarou estado de pandemia e, com isso, um conjunto de medidas foram traçadas, como o isolamento de casos suspeitos e o distanciamento físico, estratégias fundamentais para conter o aumento exponencial da doença e a sobrecarga nos serviços de saúde (MACEDO JúNIOR, 2020).

O Brasil foi o primeiro país a registrar casos de Covid-19 na América Latina e, com o avanço rápido da transmissão comunitária, muitas pessoas continuam expostas a riscos não somente biológicos, mas sociais e institucionais, que ganham relativa especificidade entre os marcadores de desigualdades do país (RODRIGUEZ-MORALES et al., 2020). Por isso, pergunta-se: as pessoas são todas iguais diante dos riscos apresentados na pandemia de Covid-19? Quando se 
afunilam as lentes, sobretudo para o Amazonas, um caso especial defronte os demais estados brasileiros, alguns fatores de vulnerabilidade têm ganhado mais destaque. Afinal, como estes elementos têm influenciado no processo de saúde-adoecimento-cuidado da pandemia no Amazonas?

Para sustentar essa discussão, utilizou-se o conceito de vulnerabilidade proposto por Ayres et al. (2003), que esclarece sobre diferentes modos de risco e suscetibilidade ao adoecimento entre sujeitos, comunidades ou cidades inteiras. Os autores evidenciam os riscos pela exposição e, de modo inseparável, propõem uma avaliação da maior ou menor disponibilidade de recursos de cuidado e proteção, isto é, incluem processos individuais, coletivos e contextuais no debate sobre vulnerabilidade. Dentro do conceito, discutem também sobre as dimensões que mutuamente se inter-relacionam e se conectam na análise panorâmica de uma dada situação de saúde.

Nessa discussão, priorizou-se a dimensão social e a dimensão programática. Na dimensão social, analisam-se cenários socioculturais que impactam nos comportamentos e práticas que se relacionam à exposição ou à proteção e, na dimensão programática, analisam-se políticas e serviços de diversos setores como elementos intervenientes no processo de vulnerabilidade. É notório que, no dia a dia dos fluxos da vida e dos modos de trabalho face a pandemia, essas dimensões se consubstanciam e se confundem, ora como fator de risco, ora como fator de proteção, mas aqui, essa separação dimensional foi utilizada apenas com fins analíticos.

Para entender as dinâmicas aplicadas à realidade do Amazonas, especialmente sobre sua capital Manaus, algumas notas reflexivas foram apresentadas ao longo deste ensaio. A utilização desse percurso metodológico não simboliza o fim dos limites formais ou a crítica que se possa fazer em relação à produção científica, mas uma forma específica de compreensão de uma realidade regional por meio de elucubrações e interpretações de fatos que aconteceram recentemente e/ou ainda estão em curso, e isso permite olhar para o passado com os fios no presente.

Para melhor explicar esse tipo pesquisa, Meneghetti (2011) esclarece que um ensaio crítico tem uma natureza diferente das estratégias classificatórias das ciências biomédicas, justamente pela sua natureza reflexiva e interpretativa. No centro desse tipo de estudo não está a relação entre o universo qualitativo ou quantitativo, mas ao contrário, prioriza-se as leituras sobre objetos ou fenômenos analisados pelos próprios ensaístas. Na essência dessa relação, Montaigne (2002) também destaca que o ensaio é uma forma da categoria crítica da própria vida, pois quem critica precisa criar condições sob as quais um objeto se torne visível a partir de outra perspectiva. Portanto, nesse trabalho, ressalta-se que não se trata de uma revisão de banco de dados, comumente conhecida como revisão narrativa, integrativa ou sistemática, mas uma leitura de campo a partir de lentes próprias das ciências sociais, atravessada por um movimento em que a própria ciência reivindica sua autonomia.

Buscou-se também o aporte de Flick, Von Kardorff e Steinke (2000) que apresentam bases essenciais para pensar um ensaio: a) uma dada realidade social deve ser vista como construção e atribuição social de significados; b) o caráter processual metodológico está na reflexão e não na seleção ou organização; c) as condições "objetivas" de vida tornamse relevantes por meio de expressões subjetivas; d) o caráter comunicativo da realidade social permite que o refazer do processo de construção das realidades sociais torne-se ponto de partida no campo da ciência.

Hoje, a Amazônia atravessa uma crise que não vivia desde a Revolta dos Cabanos, entre 1835 e 1840, e, especialmente no estado do Amazonas, a soma dos diversos fatores elencados ao longo deste ensaio se traduzem no rápido avanço da pandemia que alcança marcos nacionais dramáticos, tais como o título de primeiro estado brasileiro a ter os serviços de saúde colapsados, computando, até a data de 20 de julho de 2020. o registro de 91.389 casos confirmados e 3.200 mortes, de modo que a taxa de letalidade do vírus atingiu 8,9\%, uma das maiores do país (BRASIL, 2020). Números que justificam compreender de forma mais imediata esse cenário.

Para analisar os fatores de riscos regionais e de vulnerabilidades que contribuíram para a eclosão desta crise no estado do Amazonas, utilizou-se o aporte teórico de Ayres et al. (2003) e os documentos do campo se trataram de mídias jornalísticas, artigos, legislações, decretos, planos de contingências, e outros. Lemos et al. (2015) destacam que os documentos e as histórias que eles mesmos narram são fragmentos que não devem ser analisados como se tivessem uma coerência ou uma sequência linear, nem mesmo se deve atestá-los como de evidência científica ou não. São retalhos cheios de lacunas, silêncios, quebras e hiatos. Dessa forma, os dados não foram analisados em fluxos descritivos, a fim de identificar ou flagrar as supostas "verdades", mas de alcançar uma perspectiva analítica de um lugar subjetivo em que cada um ocupa.

Portanto, a exposição desse texto foi organizada em duas subseções que discutem, separadamente, a dimensão social, e a dimensão programática ou institucional do processo saúde-adoecimento-cuidado da Covid-19 aplicado às particularidades do estado do Amazonas. Reitera-se também que a saúde coletiva é uma área multifacetada, ou seja, não é propriamente uma disciplina científica, mas um campo que cada vez mais tem se imbricado com as ciências sociais e, 
aqui, é reforçada pela organização histórico-cultural da categoria vulnerabilidade instituída por Ayres et al. (2003). Com isso, a perspectiva adotada ao longo deste trabalho tenta romper com as polarizações do tipo - o indivíduo e o coletivo, o biológico e o social, as diferentes racionalidades (ciências sociais/ ciências naturais). Ou seja, a saúde se institui como processo movediço, e não estanque.

\section{DIMENSÃO SOCIAL}

Para estudar os pontos mais relevantes da vulnerabilidade social no enfrentamento da pandemia no contexto amazônico, não pretendeu-se abarcar todos os elementos de uma dada complexidade de organização social, mas ressaltar que a obtenção e a possibilidade de metabolização de informações, bem como o poder de incorporá-las a mudanças práticas, não dependem somente de decisões individuais, mas de aspectos sociais, culturais e econômicos situados em determinados contextos.

O Amazonas está situado na região norte do Brasil, é o maior estado do território nacional, sua população conta com 4.144.597 habitantes, sendo que a capital, Manaus, contempla 2.182.763 de pessoas deste total. O Poder Executivo do estado é chefiado pelo governador Wilson Lima, eleito em 2019 pelo Partido Social Cristão (PSC) (INSTITUTO BRASILEIRO DE GEOGRAFIA E ESTATÍSTICA, 2019).

Foi diante da confirmação do primeiro caso de Covid-19 no estado que rapidamente as autoridades locais publicaram medidas de contenção do vírus, com destaque para os seguintes decretos: Decreto no 42.061, de 16 de março de 2020, que declarou situação de emergência na saúde pública do estado do Amazonas e instituiu um Comitê Intersetorial de Enfrentamento e Combate à Covid-19 (AMAZONAS, 2020a); Decreto no 42.100, de 23 de março de 2020, que declarou estado de calamidade pública (AMAZONAS, 2020b); Decreto no 42.101, de 23 de março de 2020, que suspendeu o funcionamento de estabelecimentos comerciais e delegou à polícia militar e agentes de fiscalização da Fundação de Vigilância em Saúde (FVS) o acompanhamento do regime de quarentena (AMAZONAS, 2020c); em apoio ao comércio local, houve a liberação de linhas de crédito, objetivando minimizar os impactos financeiros da Covid-19 aos autônomos, microempreendedores individuais e profissionais liberais; e o Decreto no 42.087, de 19 de março de 2020, que determinou a suspensão das aulas da rede estadual e da atracação de cruzeiros e embarcações no porto de Manaus, além do transporte rodoviário (AMAZONAS, 2020d).

Em meio a esse cenário de disputas entre as medidas e os decretos a serem adotados pela comunidade amazonense e com uma tímida política pública de apoio financeiro para os mais vulneráveis, grande parcela desta população seguiu sua rotina de trabalho em busca de sustento, sem poder se beneficiar das medidas protetivas do distanciamento social ${ }^{1}$. Por esse ângulo, a teoria do habitus em Bourdieu (1990) mostra como o processo de socialização e a construção de identidades impõem um sistema interligado entre indivíduo e sociedade, ou seja, entre disposições individuais e coletivas, e isto se dá por meio da interiorização de novas estruturas sociais. Desse modo, ao contextualizar a vivência da pandemia, um status atípico que atinge dimensões mundiais, compreende-se que a mudança de hábitos sugere uma nova inculcação social sobre as relações sociais e culturais, uma vez que, desde o início da pandemia, as formas de trabalho, interações sociais e meios de acesso à educação, saúde e lazer traçaram um novo caminho de (in)certezas. Estas reconfigurações se manifestaram, por exemplo, através da popularização do home office, ensino a distância, shows virtuais, teleconsultas, uso de aplicativos de interação on-line para realização de eventos com familiares e amigos, dentre outros rearranjos de socialização.

A movimentação das estruturas sociais em tempos de pandemia também requer celeridade, convoca as instâncias individuais e coletivas em prol da superação da circunstância em questão, além de disseminar uma política maciça de contenção do vírus. Nesse dispositivo político, destacam-se os decretos governamentais e campanhas midiáticas que alertam para prevenção e ratificam a importância da adoção ágil de novos hábitos essenciais para o combate da Covid-19. Mas será possível que uma mudança complexa ocorra tão rapidamente? Em caso afirmativo, quais as prerrogativas biopsicossociais e políticas necessárias para promover a sensibilização em massa em prol das mudanças que o contexto requer?

Ora, apesar de todas as medidas tomadas, o Boletim Epidemiológico (no 9) divulgado no início de abril pela Secretaria de Vigilância em Saúde (SVS, 2020), apontou o Amazonas como a quarta unidade federativa com maior número de casos da doença. Em entrevista, o governador atribuiu o aumento dos casos ao descumprimento de tais determinações por parte da população e apontou que a queda no índice de isolamento físico ocorre devido ao amplo contingente de trabalhadores informais, diante disso sinalizou a possibilidade de um lockdown (BENITES, 2020). É

\footnotetext{
${ }^{1}$ A OMS (2020) recomendou a alteração do termo "distanciamento social" para "distanciamento físico", já que não houve um rompimento completo das relações interpessoais entre pessoas e/ou grupos, e as conexões sociais por meio das plataformas virtuais passaram a se configurar como um dos principais recursos mediadores das relações humanas, imputando um novo modo de vida.
} 
notório o quão importante é o isolamento, mas também se questiona de que pedagogia tem se amparado o diálogo com as comunidades - a pedagogia do medo?

O fator econômico é, como pontuado acima, um problema significativo enfrentado pela classe trabalhadora. Sobre isso, a Pesquisa Nacional por Amostra de Domicílio (PNAD) divulgada pelo IBGE (LOSCHI, 2020) aponta que o Amazonas é um dos estados com maior número de trabalhadores informais do país. A precarização do trabalho no Brasil, segundo Simões e Freitas (2016), se manifesta em decorrência dos impactos da globalização sobre a economia e, em Manaus, as mudanças nos setores agrícolas e industriais, principalmente com a implementação da Zona Franca de Manaus (ZFM), exigiam maior qualificação profissional, descartando um grande número de trabalhadores que, sem alternativas, recorreram a trabalho informal, subemprego, terceirização e outros meios.

Esse recorte socio-histórico e a crescente curva de contágio do novo coronavírus no estado podem descortinar assim, duas lentes que permitem olhar para fatores que repercutem na adesão de trabalhadores à quarentena: manter o trabalho e correr o risco de contaminação ou adotar o isolamento e não ter condições financeiras de prover o alimento? As famílias mais vulneráveis se queixam da ausência de medidas que assegurem uma renda durante este período. Nesse sentido, a matéria "Feira é fechada e feirante declara: não temos medo de morrer de coronavírus, mas de fome" ilustra o conflito vivenciado por essas pessoas (MAGALHÃES, 2020, p.2). A reportagem traz, ainda, um problema urbano importante: os bairros que inicialmente apresentaram maior incidência de casos pertenciam às classes abastadas que aderiram à quarentena sem prejuízos financeiros, enquanto as zonas remotas, que concentram pessoas de poder econômico inferior, apresentam uma crescente de contágio e ainda enfrentam dificuldades em adotar o confinamento.

Para se compreender como a distribuição de infectados na cidade reporta à desigualdade social histórica, é preciso retomar dois grandes momentos econômicos que impulsionaram o crescimento urbano de Manaus. O primeiro foi o período da borracha (1879-1912) no qual a cidade viveu um momento denominado Belle Époque, recebendo senhores da borracha e suas famílias e também operários e escravos oriundos de vários lugares do Brasil, principalmente do Nordeste. $O$ aumento populacional resultou no alargamento da cidade de forma desordenada em torno da floresta, demarcando, assim, uma intensa segregação socioespacial. O segundo momento de grande crescimento urbano ocorreu com a implementação da ZFM que atraiu para a cidade migrantes trabalhadores (NOGUEIRA; SANSON; PESSOA, 2007).
Sendo assim, entrevê-se que a explosão demográfica desencadeou o surgimento de áreas periféricas onde os estilos de vida discrepantes podem ser observados de um canto a outro da cidade, de modo que enquanto alguns residem em lugares considerados cartões postais, outros se acumulam em moradias improvisadas nas margens de rios e igarapés ou em ocupações distantes do centro urbano. Assim sendo, conclui-se que a concentração populacional em zonas suburbanas pode contribuir para a disseminação do vírus, pois impõe dificuldades socioespaciais ao acesso dos serviços básicos.

A problemática das formas de moradia ecoa, ainda, sobre as pessoas que vivem nas ruas. O levantamento estatístico realizado pela Secretaria de Estado de Justiça, Direitos Humanos e Cidadania (SEJUSC) apontou que cerca de 1.289 pessoas vivem em situação de rua em Manaus, sendo a maioria advinda de outros estados ou de cidades do interior (ALVES, 2018). Segundo Nunes (2019), grande parcela das pessoas em situação de rua reside no centro de Manaus devido à zona portuária que concentra o abastecimento de mercados e feiras, variedade comercial e aglomerações, contexto que possibilita a arrecadação de dinheiro e/ou alimento por meio de serviços informais, mendicância etc. Entretanto, devido à quarentena, o funcionamento e a circulação nesses espaços foram fortemente atingidos, bem como a sobrevivência das pessoas em situação de rua que dependem desses meios para o sustento básico. Além disso, a saúde deste grupo também se apresenta como um desafio emergente às autoridades responsáveis que precisam garantir o alcance e a proteção dessas populações.

De modo análogo, a proteção às populações indígenas tão presentes na realidade amazonense requer ações céleres a fim de evitar o risco de um genocídio. De acordo com Oliveira et al. (2020), a possibilidade de dispersão do novo coronavírus em comunidades indígenas é uma ameaça nacional até mesmo para os grupos étnicos mais isolados, incluindo a terra indígena Vale do Javari, localizada no Amazonas, cujo índice de vulnerabilidade marca a quarta posição no cenário nacional e se destaca como um dos territórios com maior concentração de povos indígenas isolados (um número que ultrapassa a faixa de seis mil habitantes). Vale ressaltar que a classificação dos índices de vulnerabilidade considera o perfil etário da população indígena, as condições de estrutura e mobilidade territorial, a disponibilidade e acesso ao sistema de saúde na comunidade e centros urbanos, dentre outros fatores.

Ainda de acordo com o estudo, é fundamental que as ações de prevenção se integrem desses fatores e, também, que mantenham ações de vigilância acerca da movimentação de grupos religiosos, garimpeiros ilegais e outros invasores nos territórios indígenas. Somado aos 
fatores mencionados e à complexidade das questões logísticas consideradas no índice de vulnerabilidade, outro aspecto que pode contribuir para ampla disseminação do vírus nesses locais é o modo de vida comunitário das populações indígenas, onde as dimensões de convivência e partilha são mais coletivas. À vista disso, pontua-se que as ameaças às comunidades indígenas representam não somente perdas físicas ou um acréscimo às estatísticas de óbitos, pelo contrário, estes riscos no contexto da Covid-19 se apresentam como uma manutenção perversa de um longo histórico de mortes de grupos étnicos causadas por doenças hospedadas em pessoas externas à realidade indígena.

Um outro problema social também tem ganhado destaque no cenário amazonense. De acordo com Vieira, Garcia e Maciel (2020), as notificações de casos de violência doméstica e familiar contra a mulher cresceram durante a pandemia. Para as autoras, trata-se de um problema de gênero enfrentado há séculos em que se naturaliza cotidianamente o poder de homens sobre mulheres e de diversos tipos de agressões; e, com a pandemia, fatores como estresse, crise econômica, principalmente em relação às despesas familiares e tarefas domésticas comumente mais atribuídas às mulheres, podem estar relacionados a este acréscimo nas estatísticas policiais. Ressaltam também que, no Brasil, estima-se que a cada sete horas, uma mulher é vítima de feminicídio que, na maioria das vezes, é praticado por parceiro afetivo ou ex.

De acordo com a Ouvidoria Nacional dos Direitos Humanos (ONDH) do Ministério da Mulher, da Família e dos Direitos Humanos (MMFDH), os telefones Disque 100 e Ligue 180 registraram um aumento de $17,97 \%$ de denúncias no mês de março de 2020 se comparado a março de 2019 (GOVERNO FEDERAL, 2020). Inversamente, em entrevista, a delegada Débora Mafra, da Delegacia Especializada em Crimes contra Mulher, relatou que, em Manaus, os registros de violência doméstica reduziram em $90 \%$ desde o início da quarentena, justificando que tal redução pode estar associada ao medo das vítimas em contrair coronavírus ao sair de casa (para denunciar) ou que o seu agressor se torne mais vulnerável ao vírus em casos de prisão. Em casos de flagrante, os registros seguem com índices altos (MARTINS, 2020).

Em concordância, acredita-se que o baixo índice de ocorrências configure subnotificação de casos, uma vez que, em cumprimento à quarentena, vários estabelecimentos públicos encontram-se inoperantes presencialmente, acarretando dúvidas nas mulheres acerca do funcionamento das delegacias e instituições de acolhimento. Além disso, há os casos em que o contexto familiar é rodeado também por vulnerabilidade econômica, podendo dificultar o acesso à informação e à solicitação destes serviços via canais de denúncias por telefone ou plataforma virtual. Outrossim, o atendimento não presencial pode acarretar na vítima incertezas quanto ao acolhimento de sua queixa e, inclusive, um empecilho para o estabelecimento de uma relação de confiança no profissional e confortabilidade no contexto, ambos aspectos necessários na abordagem de casos de violência.

Para Vieira, Garcia e Maciel (2020), o enfrentamento da violência contra a mulher em tempos de pandemia requer do poder público ações efetivas de informação, que não se restrinjam ao recebimento de denúncias por telefone. 0 Governo do Estado, com apoio da SEJUSC, lançou o informativo digital "Mulher, seus direitos não estão em quarentena!", a cartilha apresenta dados estatísticos, orienta acerca dos tipos de violência e sobre as formas de efetuar a denúncia (AMAZONAS, 2020f).

Nos casos de violência contra pessoas lésbicas, gays, bissexuais, travestis e transexuais (LGBT) nota-se a falta de registros atualizados. Conforme balanço do Disque 100, no primeiro semestre de 2018, o Amazonas estava entre os dez estados brasileiros com o maior índice de denúncias de violência contra as populações LGBT. Contudo, entre 2017 a 2019, o Anuário Brasileiro de Segurança Pública elaborado pelo Fórum Brasileiro de Segurança Pública revelou que apenas doze estados apresentaram dados referentes ao assunto e o Amazonas não estava nessa lista (SILVA, 2019).

A omissão dos dados reais de violência imputa ao estado a violação dos direitos dessas populações e, em meio à pandemia, a violência institucional sofrida por esse público tem ganhado maior amplitude. Representantes dos movimentos LGBT denunciaram outras problemáticas, tais como o acesso a bens e serviços que também foi prejudicado, uma vez que devido ao isolamento a retirada de documentos para pessoas trans estagnou, impactando diretamente no acesso a benefícios assistenciais. Além disso, existem muitas pessoas LGBT vivendo em situação precária ou mesmo na rua, pois não são aceitas no seio familiar e precisam sobreviver por conta própria, sem mencionar as dificuldades em conseguir empregos formais, tendo em vista o preconceito que as coloca em desvantagem perante a maioria (SANTOS, 2020). Desse modo, verifica-se que o enfrentamento da pandemia por populações LGBT reforça o histórico de marginalização e a escassez de oportunidades e liberdade destes grupos.

O contexto das violências abrange, ainda, crianças e adolescentes. Segundo Oliveira et al. (2020), estes números são uma constante na realidade nacional, sobretudo amazônica, e os dados de Manaus revelam que entre os anos de 2009 a 2016 a violência do tipo sexual foi a mais registrada, com cerca de 10.333 casos notificados, sendo que 
em $43 \%$ dos casos com crianças e em $24 \%$ com adolescentes os agressores possuíam relações parentais com as vítimas ou eram pessoas próximas às famílias. As violências infantojuvenis envolvem uma relação hierárquica de desigualdade amparada no silêncio, passividade e limitada autonomia das vítimas. Sendo assim, acredita-se que, durante a pandemia, estes dados podem se agravar à medida que o confinamento sujeita a convivência regular das crianças e adolescentes com seus abusadores, enquanto as afasta das redes de apoio e segurança, como as escolas, por exemplo.

De acordo com lamamoto (2018), o crescimento sistemático das desigualdades sociais impulsionado desde a década de noventa pela globalização resulta em instabilidade econômica constante e, no Brasil, essa instabilidade se relaciona com a crise no cenário político que, desde o impeachment da ex-presidenta Dilma Rousseff, em 2016, levou ao poder representantes políticos vinculados aos interesses de grandes empresários. Após a ruptura constitucional, o orçamento público se direciona a estes grupos, à medida que promove o desmonte dos direitos sociais e das políticas públicas que atendem às minorias sociais. A esse respeito, a autora cita como exemplos a privatização, a reforma trabalhista e da previdência que contribuem para a precarização do trabalho, o aumento do desemprego e de ocupações informais, os ataques contra a universidade pública e os incentivos estatais direcionados a ciência e tecnologia, as ameaças às demarcações de terras indígenas e outras políticas assistencialistas.

Diante disso, compreende-se que a realidade amazonense sinaliza a existência fortemente marcada pelos fatores relacionados a classe, gênero, etnia e cultura que influenciam as condições de enfrentamento da pandemia de Covid-19 no estado e que, sem a devida assistência estatal, dificilmente serão superadas agilmente. A perspectiva interseccional impõe, como desafio, considerar os vários modos de vida da população, a fim de desenvolver planos de ação mais realistas e que supram as necessidades das diversas camadas sociais, fornecendo, dessa maneira, um amparo efetivo através de medidas protetivas e democráticas. Afinal, nos parece que o cumprimento do distanciamento físico não depende apenas de uma escolha individual, mas considera questões relacionadas ao privilégio social de uma minoria que obtém apoio substancial da máquina pública, cuja prática institucional potencializa os abismos sociais que regularmente colocam em desvantagem as populações mais vulneráveis.

\section{DIMENSÃO PROGRÁMATICA}

O plano de análise da dimensão programática (ou institucional) de vulnerabilidade busca avaliar como, em dadas circunstâncias sociais, as instituições, especialmente as de saúde, reproduzem, quando não mesmo aprofundam, as condições de vulnerabilidade social. A vida das pessoas nas sociedades sempre esteve mediada pelas diversas instituições sociais e, com a pandemia de Covid-19, algumas delas se tornaram mais visíveis, por isso serão apontados alguns elementos institucionais do Amazonas.

Dentre os principais empecilhos para a organização das diferentes linhas de cuidado em saúde que configuram a conformação do Sistema Único de Saúde (SUS), despontam principalmente as desigualdades socioeconômicas vigentes no país, que são agravadas pela limitada governança das autoridades sanitárias nos municípios e regiões menos favorecidas, em particular, na região amazônica. Um mês após o primeiro caso confirmado, o SUS do Amazonas colapsou, com uma ocupação total dos 118 leitos de UTI (Unidade de Terapia Intensiva) disponíveis à época (MENDONÇA, 2020). O estado já vivia uma escassez de recursos antes da chegada do novo coronavírus que, somada às condições regionais, se tornou um cenário propício à ruína.

A literatura de Garnelo, Sousa e Silva (2017) já apontava que a rede de serviços de saúde no estado era insuficiente, com destaque para os problemas de fixação de recursos humanos, principalmente nos municípios de pequeno porte. Vale destacar que os dispositivos de média e alta complexidade estão presentes, quase que exclusivamente, nas capitais, em prejuízo da população que vive nas áreas mais remotas. O repasse dos recursos federais ainda é abaixo da média per capita nacional e a infraestrutura sanitária é frágil, convergindo em pouca resolutividade das necessidades de saúde básicas ou especializadas. Existe também pouca sensibilidade para os condicionantes regionais em saúde e, como previsto, a Covid-19 trouxe à tona todos esses problemas.

A rede de assistência no Amazonas foi ampliada devido à crescente de casos e à falta de equipamentos, inclusive de proteção individual, que culminou na contaminação de 1.279 (5,5\% do total de 23.176) profissionais da saúde até o dia 02 de maio (FUNDAÇÃO DE VIGILÂNCIA EM SAÚDE DO AMAZONAS, 2020). Para isso, o governo do estado recrutou novos profissionais de saúde, inaugurou outras unidades de campanha, firmou parceria com a Universidade Estadual do Amazonas, para formatura especial de novos profissionais, e com a Moto Honda da Amazônia, para a produção de protótipos de respiradores e Equipamentos de Proteção Individual (AMAZONAS, 2020e).

Em paralelo ao colapso no sistema de saúde, observa-se também a crise do sistema funerário. De acordo com Araújo e Freire (2020), no mês de abril foi registrado um aumento de $179,5 \%$ no número de mortes, incluindo sepultamentos e 
cremações, que equivale a 2.435 óbitos, em comparação aos dados de abril de 2019 que computaram 871 mortes. O aumento de óbitos ocorridos nesse mês causou mudanças no protocolo dos enterros realizados pelo maior cemitério público da capital amazonense, o qual passou a realizar sepultamentos no período noturno e em valas comuns.

O presidente Jair Bolsonaro, ao ser questionado em uma coletiva de imprensa sobre as vítimas fatais de Covid-19, afirmou: "Não sou coveiro, tá?" (THE LANCET, 2020). Entre este e outros pronunciamentos considerados incomuns para um chefe de estado, o estudo de Mariani, Gagete-Miranda e Rettl (2020) apontou o crescimento equivalente a $18,9 \%$ dos casos de Covid-19 em cidades onde o presidente Jair Bolsonaro obteve forte eleitorado. Na pesquisa, foram considerados 255 municípios e os efeitos causados sobre seus habitantes após o presidente ter participado de uma manifestação pró-governo onde apertou as mãos de alguns apoiadores, contrariando as recomendações do Ministério da Saúde para evitação de aglomerações e contato físico.

Manaus está entre as capitais brasileiras que, em 2018, contabilizaram a maioria dos votos pró-Bolsonaro e isto pode dar indícios de que as ações do presidente exercem influência direta sobre seus apoiadores, bem como pode impactar no cumprimento da quarentena por parte destes. Nessa lógica, além do alinhamento ideológico ao presidente, outras estratégias têm sido utilizadas por Jair Bolsonaro para o enfraquecimento do combate à Covid-19, com destaque para a insistência do embate entre a saúde versus a economia, onde a classe proletária precisa escolher entre aderir o isolamento físico ou optar pela manutenção de seus empregos para o sustento básico. O conceito de necropolítica, desenvolvido por Mbembe (2016), aponta uma relação entre a soberania do Estado e a mortalidade de determinados grupos sociais, levantando a discussão da existência de "vidas matáveis". É uma espécie de tecnologia de produção da morte nos tempos contemporâneos. A guerra não constitui apenas um único meio para obter determinada soberania, mas também uma forma de exercer o direito de matar. Ao se imaginar a política como uma destas formas, deve-se interrogar: "qual é o lugar reservado à vida, à morte e ao corpo humano (em particular ao corpo adoecido)? Que lugar ocupa dentro da ordem do poder?" (MBEMBE, 2016, p. 108).

Apesar do conceito de necropolítica ser próprio da literatura de Mbembe (2016), Butler (2017) também traz reflexões sobre os enquadramentos seletivos e as operações específicas de poder na sociedade. Como os dispositivos agem delimitando o que pode ser ou não considerado como vida, ou como prioridade de vida. Com a pandemia, a chegada de um vírus deflagra e cronifica uma série de desigualdades e processos que incidem diferentemente sobre os sujeitos.

A pandemia tem impulsionado também a produção de diversas fake news relacionadas, principalmente, ao tratamento da doença. A cloroquina está entre as substâncias associadas às falsas notícias, principalmente após os presidentes dos Estados Unidos e do Brasil terem atribuído potencial de cura ao medicamento enquanto ainda está em fase de teste. Essas declarações imprudentes provocaram buscas desenfreadas pelo fármaco, de modo que as farmácias zeraram os estoques do medicamento em todo o mundo, prejudicando o tratamento de pacientes que fazem uso prolongado da substância (FERNANDES, 2020).

A cloroquina é utilizada há mais de 70 anos no tratamento de malária e comorbidades reumatológicas, que são endêmicas na região amazônica. A substância e outros compostos semelhantes foram utilizados em surtos anteriores de outros coronavírus, como em 2002 na China (SARS-CoV) e em 2012 (MERS-CoV) no oriente médio (IMOTO et al., 2020), e, no Brasil, o Amazonas tem sido um forte campo de pesquisa na malária e, atualmente, com a Covid-19, formou a primeira equipe brasileira empenhada no estudo da substância. Em abril deste ano, os resultados preliminares dessa pesquisa revelaram que altas doses da substância administradas por dez dias podem acarretar maior risco de arritmia cardíaca, ressaltaram os riscos da automedicação e salientaram que o remédio não previne a Covid-19 (BORBA et al., 2020). Após a divulgação, os pesquisadores foram duramente criticados por Jair Bolsonaro e seu filho, o parlamentar Carlos Eduardo Bolsonaro, e, por meio de nota, a Fiocruz reportou ameaças aos profissionais que passaram a receber escolta policial (OLIVEIRA, 2020).

O conflito federativo entre os diferentes níveis de governo enfraquece o controle da pandemia e, mais uma vez, expõe as populações vulneráveis. Para ilustrar este cenário, pode-se exemplificar as medidas tomadas em relação às pessoas em situação de rua citadas anteriormente na ótica social. A matéria de Maisonnave (2020) para o jornal Folha de São Paulo indicou que apenas $5 \%$ dos moradores de rua em Manaus estavam abrigados no espaço organizado pela SEJUSC e outras entidades de assistência social na Arena Amadeu Teixeira, o local, com potencial para recebimento de 350 pessoas, abrigava somente 65 , em um cenário onde, segundo a Pastoral do Povo da Rua de Manaus, existem cerca de 2.000 pessoas (contando com venezuelanos) vivendo nessas condições.

Devido à insuficiência do abrigo, muitos moradores de rua se aglomeraram nas imediações da arena, dormindo sobre papelões, utilizando banheiros químicos e sem máscaras de proteção. Fato que impeliu a Defensoria Pública do Estado e os Ministérios Públicos Federal e do Trabalho a 
ingressarem com ação civil pública contra o governo do Amazonas e a prefeitura de Manaus, expondo que os representantes do poder público e entes federativos pouco fazem para disponibilizar um espaço seguro às pessoas em situação de rua. No processo constam, ainda, medidas alternativas para auxiliar e garantir os direitos desta população, tais como fornecimento de pensão ou aluguel social, identificação de imóveis públicos e privados que estejam ociosos, a fim de utilizá-los como moradia temporária. Assim sendo, percebe-se o quanto a ineficiência das autoridades públicas, ancoradas na ausência de coordenação com o governo federal, coloca em desvantagem as populações que são atingidas por extrema vulnerabilidade social e deflagra, principalmente, a negligência da saúde coletiva.

Novamente, testemunha-se como a crise política citada na dimensão social impacta nas condições de enfrentamento da Covid-19 no Amazonas. A drenagem dos recursos públicos em favor do mercado financeiro é simbolizada, principalmente, desde a aprovação da Emenda Constitucional $n^{\circ}$ 95/2016 que congela por vinte anos as despesas primárias relacionadas aos direitos sociais, como exemplo a saúde. Se a aprovação da emenda na época já significava o perecimento dos direitos sociais, atualmente, sua manutenção indica o desinteresse dos poderes públicos em garantir condições mínimas de atenção aos menos favorecidos. Além das restrições a nível federal, o desvio de verbas públicas é outra realidade presente no Amazonas, exemplo disto é a Operação Maus Caminhos, deflagrada em 2016 pelo Ministério Público Federal, que investiga um esquema de desvio milionário de recursos e má gestão da saúde pública estadual, com poucos médicos, salários atrasados e falta de investimento, este cenário contribuiu fortemente para o desastre sanitário vivenciado atualmente (TROSTA, 2020).

Em vista desse contexto, verifica-se que, enquanto os recursos ao mercado financeiro obtiveram liberações rápidas, o repasse de insumos ao SUS, a ampliação de recursos para áreas prioritárias, o pagamento da renda básica emergencial às populações carentes e o acolhimento de outras demandas sociais caminham morosamente. Deste modo, nota-se que, não obstante as tentativas do governo estadual em traçar planos de contenção desde os primeiros pacientes acometidos com a Covid-19 até o colapso sanitário, as principais dificuldades enfrentadas e aqui descritas fazem parte de um conglomerado de negligências e práticas criminosas que já ocorrem há anos no Amazonas e que, em um momento de crise como este, previam um prognóstico desastroso.

\section{CONSIDERAÇÕES FINAIS}

A crise no Amazonas ocasionada pela pandemia é fortemente atravessada pela ótica da determinação social em saúde. O enfoque à dimensão social ressalta os problemas que o estado precisa enfrentar para além da Covid-19, tais como: o grande percentual de subempregos e informalidades, o crescimento urbano desordenado e segregacionista que cria zonas periféricas e dificulta o acesso aos serviços básicos, a invisibilização das minorias e a naturalização de violências. Outrossim, também evoca os efeitos de uma política governamental inclinada à priorização dos interesses corporativos da elite brasileira, em detrimento das questões sociais.

Através da dimensão programática, verifica-se a fragilidade institucional dos governos em reconhecer as reivindicações sociais e financeiras tão fundamentais para o êxito do distanciamento físico e da contenção do novo coronavírus nas camadas socialmente desfavorecidas. Sendo assim, o cenário calamitoso deflagrou a necessidade do desenvolvimento de ações realisticamente compatíveis com as vulnerabilidades regionais para o enfrentamento efetivo da pandemia, envolvendo, principalmente, os dispositivos do SUS.

Por mais que o uso de máscara seja uma premissa adotada mundialmente como prevenção e proteção sanitária, a pandemia "removeu as máscaras da vida", e expôs ainda mais as desigualdades, embarreiramentos, exclusões e fragilidades no campo das políticas públicas. $O$ que se tem de mais revolucionário, nesse cenário da pandemia, é a evocação de um passado para compreender o presente e tentar modificar o futuro. Isso mostra a importâncias de se acionar uma dimensão ética do cuidado no plano macropolítico e micropolítico e que esta seja capaz de romper com os ciclos que produzem mortificação e assim, abrir espaço para a criação de novas relacionalidades.

Por fim, pode-se dizer que em meio às inúmeras reflexões lançadas sobre as vulnerabilidades do processo de saúde-adoecimento-cuidado em face da Covid-19 no estado do Amazonas, estas são anteriores a pandemia. E com o cenário de crise generalizada, amplificaram-se as precarizações das próprias vidas, "deixando morrer" aqueles que já estavam demarcados pelas desigualdades locais e nacionais. Ou seja, o Amazonas, como estado brasileiro de maior dimensão geográfica, contendo vasta pluralidade cultural, necessita de ações intersetoriais que reconheçam as vulnerabilidades como fatores que influenciam na garantia do direito à saúde e à proteção ao alcance de todos. 


\section{REFERÊNCIAS}

ALVES, D. Sobrevivendo: censo aponta que mais de mil pessoas "moram" nas ruas de Manaus. A Crítica, Manaus, 12 abr. 2018. Disponível em: https://www.acritica.com/channels/manaus/news/sobre vivendo-censo-aponta-que-mais-de-mil-pessoas-moramnas-ruas-de-manaus. Acesso em: 20 abr. 2020.

AMAZONAS (Estado). Decreto $n^{\circ}$ 42.061, de 16 de março de 2020. Diário Oficial do Estado do Amazonas, Poder Executivo, Amazonas, AM, 16 mar. 2020a.

AMAZONAS (Estado). Decreto $n^{\circ} 42.100$, de 23 de março de 2020. Diário Oficial do Estado do Amazonas, Poder Executivo, Amazonas, AM, 23 mar. 2020b.

AMAZONAS (Estado). Decreto $n^{\circ} 42.101$, de 23 de março de 2020. Diário Oficial do Estado do Amazonas, Poder Executivo, Amazonas, AM, 23 mar. 2020c.

AMAZONAS (Estado). Decreto $n^{\circ} 42.087$, de 19 de março de 2020. Diário Oficial do Estado do Amazonas, Poder Executivo, Amazonas, AM, 31 mar. 2020d.

AMAZONAS (Estado). Secretaria de Estado de Saúde. Indústria e UEA apresentam solução para produção de respiradores no PIM. Manaus: SUSAM, 2020e. Disponível em: $\quad<$ http://www.saude.am.gov.br/visualizarnoticia.php?id=4389>. Acesso em: 20 abr. 2020.

AMAZONAS (Estado). Secretaria de Estado de Justiça, Direitos Humanos e Cidadania. Informativo digital "Mulher, seus direitos não estão em quarentena" é lançado pela Sejusc com canais de denúncia. Manaus: SEJUSC, 2020f. Disponível em: http://www.sejusc.am.gov.br/informativo-digital-mulherseus-direitos-nao-estao-em-quarentena-e-lancado-pelasejusc-com-canais-de-denuncia/. Acesso em: 05 mai. 2020.

ARAÚJO, A; FREIRE, M. Manaus registra quase 2,5 mil sepultamentos em abril. Prefeitura de Manaus, Manaus, 01 maio 2020.2 Disponível em: http://www.manaus.am.gov.br/noticia/manaus-registraquase-25-mil-sepultamentos-em-abril/. Acesso em: 05 mai. 2020.

AYRES, J. R. C. M. et al. O conceito de vulnerabilidade e as práticas de saúde: novas perspectivas e desafios. In: CZERESNIA, D.; FREITAS, C. M. (Org.). Promoção da saúde: conceitos, reflexões e tendências. Rio de Janeiro: Fiocruz, 2003. p. 117-139.

BENITES, A. Governador do Amazonas: "90\% dos leitos estão com pacientes de Covid-19. É uma corrida contra o tempo". El País, Brasília, 13 abr. 2020. Disponível em: https://brasil.elpais.com/brasil/2020-04-14/governadordo-amazonas-90-dos-leitos-estao-com-pacientes-de- covid-19-estamos-numa-corrida-contra-o-tempo.html. Acesso em: 17 abr. 2020.

BORBA, M. G. S. et al. Chloroquine diphosphate in two different dosages as adjunctive therapy of hospitalized patients with severe respiratory syndrome in the context of coronavirus (SARS-CoV-2) infection: Preliminary safety results of a randomized, double-blinded, phase Ilb clinical trial (CloroCovid-19 Study). MedRxiv, p. 1-30, 2020.

BOURDIEU, P. Coisas ditas. São Paulo: Brasiliense, 1990.

BRASIL. (Constituição de 1988). Emenda Constitucional de $\mathrm{n}^{\circ}$ 95, de 15 de dezembro de 2016. Altera o Ato das Disposições Constitucionais Transitórias, para instituir o Novo Regime Fiscal, e dá outras providências. Diário Oficial da União, Brasília, DF, 16 dez. 2016. Disponível em:

http://www.planalto.gov.br/ccivil 03/constituicao/emen das/emc/emc95.htm. Acesso em: 14 maio 2020.

BRASIL. Ministério da Saúde. Coronavírus Brasil - Painel Geral COVID-19. 2020. Disponível em: https://covid.saude.gov.br/. Acesso em: 20 jul. 2020.

BUTLER, J. Quadros de Guerra. Rio de Janeiro: Civilização Brasileira, 2017.

FERNANDES, D. Coronavírus: testes com cloroquina causam corrida a hospitais e dividem médicos na França. BBC News Brasil, 26 mar. 2020. Disponível em: https://www.bbc.com/portuguese/brasil-52044400. Acesso em: 18 abr. 2020.

FLICK, U.; KARDORFF, E. V.; STEINKE, I. (Orgs.). Was ist qualitative Forschung? Einleitung und Überblick. [O que é pesquisa qualitativa: uma introdução]. In: FLICK, U.; KARDORFF, E. V.; STEINKE, I (Orgs.), Qualitative Forschung: Ein Handbuch [Pesquisa qualitativa - um manual]. Reinbek: Rowohlt, 2020.p. 13-29.

FUNDAÇÃO DE VIGILÂNCIA EM SAÚDE DO AMAZONAS (FVS). Manaus tem $5,5 \%$ de profissionais de saúde infectados pelo novo coronavírus. Manaus: FVS, 2020. Disponível em: $\quad$ http://www.fvs.am.gov.br/noticias view/3884. Acesso em: 05 maio 2020.

GARNELO, L; SOUSA, A. B. L.; SILVA, C. O. Regionalização em Saúde no Amazonas: avanços e desafios. Ciência \& saúde coletiva, Rio de Janeiro, v. 22, n. 4, p. 1225-1234, abr. 2017.

GOMES, M. M. S. Trabalho precário em Manaus: os carreteiros da Feira Manaus Moderna. 2014. $135 \mathrm{f}$. Dissertação (Mestrado em Sociedade e Cultura na Amazônia) - Universidade Federal do Amazonas, Manaus, 2014.

GOVERNO FEDERAL (BR). Ministério da Mulher, da Família e dos Direitos Humanos. Coronavírus: sobe o número de ligações para canal de denúncia de violência doméstica na quarentena. Brasília: MMFDH, 2020. Disponível em: 
https://www.gov.br/mdh/pt-br/assuntos/noticias/20202/marco/coronavirus-sobe-o-numero-de-ligacoes-paracanal-de-denuncia-de-violencia-domestica-naquarentena. Acesso em: 20 abr. 2020.

IAMAMOTO, M. V. "Questão social" no Brasil: relações sociais e desigualdades. ConCienciaSocial, v. 2, n. 3, jun. 2018.

IMOTO, M. A. et al. Cloroquina e Hidroxicloroquina no tratamento da COVID-19: sumário de evidências. Comunicação em Ciências da Saúde, v. 31, n. 1, p. 17-30, 2020.

INSTITUTO BRASILEIRO DE GEOGRÁFIA E ESTATÍSTICA. Estimativas da População Residente no Brasil e Unidades da Federação com data de Referência em 10 de julho de 2019. IBGE, 1 jul. 2019. Disponível em: https://www.ibge.gov.br/estatisticas/sociais/populacao/9 103-estimativas-de-populacao.html?=\&t=resultados. Acesso em: 18 abr. 2020.

LEMOS, F. C. S.; GALINDO, D.; REIS JÚNIOR, L. P.; MOREIRA, M. M.; MAGALHÃES, A. G. B. Análise documental: algumas pistas de pesquisa em psicologia e história. Psicologia em Estudo, v. 20, n. 3, p. 461-469, 30 set. 2015.

LOSCHI, M. Desemprego cai em 16 estados em 2019, mas 20 têm informalidade recorde. Agência IBGE Notícias, Brasil, 14 abr. 2020. Disponível em: https://agenciadenoticias.ibge.gov.br/agencianoticias/2012-agencia-de-noticias/noticias/26913desemprego-cai-em-16-estados-em-2019-mas-20-teminformalidade-recorde. Acesso em: 17 abr. 2020.

MACEDO JÚNIOR, A. M. Covid-19: calamidade pública. Medicus, v. 2, n. 1, p. 1-6, jan. 2020.

MAGALHÃES, L. Feira é fechada e feirante declara: "não temos medo de morrer de coronavírus, mas de fome". D24AM, Amazonas, 5 abr. 2020. Disponível em: https://d24am.com/coronavirus-no-amazonas/feira-efechada-e-feirante-declara-nao-temos-medo-de-morrerde-coronavirus-mas-de-fome/. Acesso em: 19 abr. 2020.

MAISONNAVE, F. Com Manaus à beira do colapso por coronavírus, só $5 \%$ dos moradores de ruas estão abrigados. Folha de S. Paulo, São Paulo, 8 abr. 2020. Disponível

em: https://www1.folha.uol.com.br/cotidiano/2020/04/commanaus-a-beira-do-colapso-por-coronavirus-so-5-dosmoradores-de-ruas-estao-abrigados.shtml. Acesso em: 20 abr. 2020.

MARIANI, L. A.; GAGETE-MIRANDA, J.; RETTL, P. Words can hurt: how political communication can change the pace of an epidemic. Centre for Economic Policy Research, v. 12, p. 104-137, 1 mai. 2020. Disponível em: https://cepr.org/sites/default/files/news/CovidEconomics 12.pdf. Acesso em: 10 mai. 2020.

MARTINS, D. Registros de violência doméstica diminui durante quarentena em Manaus. Em Tempo, Manaus, 30 mar. 2020. Disponível em: https://d.emtempo.com.br/amazonas/196378/registrosde-violencia-domestica-diminui-durante-quarentena-emmanaus. Acesso em: 20 abr. 2020.

MBEMBE, A. Necropolítica. Arte e Ensaios, v. 2, n. 32, 2016. MENDONÇA, A. Saiba por que Manaus entrou em rápido colapso com os casos de COVID-19. Estado de Minas, Minas Gerais, 23 abr. 2020. Disponível em: https://www.em.com.br/app/noticia/nacional/2020/04/ 23/interna nacional,1141074/saiba-porque-manausentrou-em-rapido-colapso-com-os-casos-de-covid-

19.shtml. Acesso em: 10 mai. 2020.

MENEGHETTI, F. K. O que é um ensaio-teórico?. Revista de administração contemporânea, Curitiba, v. 15, n. 2, p. 320-332, Abr. 2011. Disponível em: http://www.scielo.br/scielo.php?script=sci_arttext\&pid= S1415-65552011000200010\&lng=en\&nrm=iso. Acesso em: 01 Ago. 2020.

MONTAIGNE, M. Os ensaios: livro I. São Paulo: Martins Fontes, 2002.

NOGUEIRA, A. C. F.; SANSON, F.; PESSOA, K. A expansão urbana e demográfica da cidade de Manaus e seus impactos ambientais. In: XIII Simpósio Brasileiro de Sensoriamento Remoto, Florianópolis, Brasil, v. 21, p. 5427-5434, abr. 2007.

NUNES, J. S.; SOUZA, T. J.; FANARO, G. B. Traços identitários e confluências da culinária amazonense. Revista Ensino, Saúde e Biotecnologia da Amazônia, v. 1, n. especial, p. 1-1, jun. 2019.

OLIVEIRA, B. Pesquisadores do Amazonas sofrem ameaças após estudo com Cloroquina. Em Tempo, Manaus, 17 abr. $2020 . \quad$ Disponível em: https://d.emtempo.com.br/amazonas/199598/pesquisad ores-do-amazonas-sofrem-ameacas-apos-estudo-comcloroquina. Acesso em: 05 maio 2020.

OLIVEIRA, N. F. et al. Violência contra crianças e adolescentes em Manaus, Amazonas: estudo descritivo dos casos e análise da completude das fichas de notificação, 20092016. Epidemiologia e Serviços de Saúde, v. 29, abr. 2020.

OLIVEIRA, U. et al. Modelagem da vulnerabilidade dos povos indígenas no Brasil ao covid-19. Instituto Socioambiental, 2020.

RODRIGUEZ-MORALES, A. J. et al. COVID-19 in Latin America: The implications of the first confirmed case in Brazil. Travel medicine and infectious disease, fev. 2020.

SANTOS, I. População LGBTI no Amazonas fica mais vulnerável durante a pandemia. Dom Total, Manaus, 18 
mai. 2020. Disponível em:

https://domtotal.com/noticia/1445626/2020/05/populac ao-Igbti-no-amazonas-fica-mais-vulneravel-durante-apandemia/. Acesso em: 19 mai. 2020.

SIMÕES, A. L.; FREITAS, C. M. D.. Análise sobre condições de trabalho de Equipe de Saúde da Família, num contexto de vulnerabilidades, Manaus (AM). Saúde debate, Rio de Janeiro, v. 40, n. 109, p. 47-58, Jun. 2016 . Disponível em:

http://www.scielo.br/scielo.php?script=sci_arttext\&pid= S0103-11042016000200047\&Ing=en\&nrm=iso. Accesso em: 01 Ago.. 2020.

SECRETARIA DE VIGILÂNCIA EM SAÚDE (SVS). Boletim Epidemiológico $n^{\circ}$ 09: situação epidemiológica da Covid19 doença pelo Coronavírus 2019. Ministério da Saúde, Brasília, 11 abr. 2020. Disponível em: https://portalarquivos.saude.gov.br/images/pdf/2020/Ap ril/12/2020-04-11-BE9-Boletim-do-COE.pdf. Acesso em: 17 abr. 2020.

SILVA, V. R. Escassez de dados expõe invisibilização da violência contra população LGBT+ na segurança pública. Gênero e Número, 1 set. 2019. Disponível em: http://www.generonumero.media/escassez-de-dadosviolencia-lgbt/. Acesso em: 02 maio 2020.

SOARES, I. "Não sou coveiro", diz Bolsonaro ao ser questionado sobre mortes por Covid. Correio Brasiliense, Brasília, 20 abr. 2020. Disponível em: https://www.correiobraziliense.com.br/app/noticia/politi ca/2020/04/20/interna politica,846638/nao-soucoveiro-diz-bolsonaro-ao-ser-questionado-sobre-mortespor-c.shtml. Acesso em: 05 mai. 2020.

TROSTA, W. No Amazonas, corrupção e má gestão agravam situação durante pandemia do coronavírus. Estadão, São Paulo, 13 mai. 2020. Disponível em: https://saude.estadao.com.br/noticias/geral,noamazonas-corrupcao-e-ma-gestao-agravam-situacaodurante-pandemia-do-coronavirus,70003300938. Acesso em: 22 mai. 2020.

THE LANCET. COVID-19 in Brazil: "So what?". Lancet, Londres (Inglaterra), v. 395, n. 10235, p. 1461, 2020. Disponível em:

https://www.thelancet.com/pdfs/journals/lancet/PIIS014 0-6736(20)31095-3.pdf. Acesso em: 22 mai. 2020

VIEIRA, P. R.; GARCIA, L. P.; MACIEL, E. L. N. Isolamento social e o aumento da violência doméstica: o que isso nos revela?. Revista Brasileira de Epidemiologia, v. 23, abr. 2020. 